\title{
Stochastic frontiers, productivity effects and development projects
}

\author{
Boris E. Bravo-Ureta* \\ Department of Agricultural and Resource Economics, and Department of Economics, University of Connecticut, \\ USA, and Department of Agricultural Economics, University of Talca, Chile
}

Received: 3 February 2014

Revised: 29 March 2014

Accepted: 30 March 2014

\begin{abstract}
A common objective of many development projects is to promote output growth as well as better management in order to improve incomes and reduce poverty. Technically, the purpose is to induce upwards shifts in the production frontier (i.e., technological change) while also promoting better management (i.e., narrowing the gap from the frontier). Given the link between managerial performance and technical efficiency, stochastic production frontiers are well suited for the task from a methodological point of view. Despite this suitability, work linking stochastic frontiers with impact evaluation methods has just begun and a major hurdle is resolving biases that might arise from selection on observables and unobservables. This article provides an overview of how impact evaluation and stochastic frontiers, two well-established areas in applied econometrics, are being brought together to shed light on the productivity effects of agricultural development interventions.
\end{abstract}

Keywords: impact evaluation, stochastic production frontiers, selection bias, propensity score matching, technological change, technical efficiency

JEL Classification Codes: D24, O22, Q12, Q16

\section{Introduction}

The purpose of this article is to provide an overview of how two well-established fields in applied economics --impact evaluation and production frontiers-- can be brought together to shed light on the effects of development projects on productivity.

\footnotetext{
*E-mail: boris.bravoureta@uconn.edu.
}

Citation: Bravo-Ureta, B.E. (2014) Stochastic frontiers, productivity effects and development projects, Economics and Business Letters, 3(1), 51-58. 
Work focusing on evaluating the impact of development projects, funded by a wide range of organizations in the pursuit of a broad set of objectives, has enjoyed dramatic growth in recent years (IEG, 2011; Gertler et al., 2011). This work has evolved largely as a response to the rising interest from donor organizations to have empirical documentation that can be used to gage the effectiveness of the assistance that is provided, particularly for projects designed to decrease poverty (Ravallion, 2008). A specific impetus for impact evaluations has been the implementation of the Millennium Development Goals and the need to support funding requests with solid evidence of progress toward the attainment of such goals (Khandker et al., 2010; World Bank, 2006).

The second sub-field of interest here concerns the production frontier literature that also has enjoyed remarkable growth, both methodologically and empirically, over the past few decades and is now a vibrant specialty in economics (Fried et al., 2010; Cooper and Lovell, 2011; BravoUreta et al., 2007). Production frontier models have been applied to the measurement of productivity and technical efficiency in a wide range of economic activities including banking, hospitals, airlines, educational institutions, and many areas in agriculture. An important issue for this paper is the link between managerial performance and technical efficiency that was established early on by several authors (Mundlak, 1961; Hoch, 1976) and more recently by Triebs and Kumbhakar (2013), and Martin and Page (2003).

A common objective of many agricultural development projects is to promote output growth as well as better management in order to improve incomes and reduce poverty (e.g., Cavatassi et al., 2011; Bravo-Ureta et al., 2011; Maffioli et al., 2011). In other words, the purpose is often to induce upward shifts in the production frontier while also promoting better management. A useful example is the provision of improved seed varieties along with extension services focusing on improving farm management. The intended effect of facilitating the access and use of improved seed varieties is to promote output growth by shifting the production frontier upwards. On the other hand, the support for extension services is to enhance managerial performance, i.e., to increase technical efficiency, which implies moving toward the frontier.

Therefore, stochastic production frontiers (SPF) seem well suited to evaluate the impact of projects that are designed to promote improved technologies to increase output while also attempting to enhance productivity by improving human capital and managerial performance. Despite this suitability, very few studies have used SPF models to evaluate impact. Two closely related papers, by Taylor and Shonkwiler (1986) and Taylor, Drummond and Gomes (1986), evaluated the impact of the PROMEDATA agricultural credit program in Brazil on technical and allocative efficiency. More recently, Dinar et al. (2007) applied an SPF model to evaluate the impact of agricultural extension on the performance of farmers in Crete. A shortcoming of these three papers is that selectivity bias, which constitutes an important challenge in impact evaluation work, is ignored. In fact, we can speculate that one of the reasons that might explain the lack of reliance on SPF models in impact evaluation work is precisely the recognition that selectivity bias is problematic in such models. Therefore, in what follows we provide an overview of some recent progress in dealing with selectivity bias and impact evaluation when using cross sectional data. We end by briefly proposing efforts to expand this line of work to two round panel data models. 


\section{Impact evaluation in an experimental world}

The purpose of impact evaluation is to determine the performance of a program in terms of achieving a clearly specified objective(s) compared to a well-defined control group or counterfactual. The ideal counterfactual is what would have happened to beneficiaries had they not participated in the intervention. Clearly, both states of nature are not possible for the same individuals and much of the challenge is to construct a credible counterfactual (Ravallion, 2008). The golden rule for impact evaluation is the randomized or experimental design which can be a straightforward way to evaluate the impact of a project and we now briefly explain why this is the case (Duflo et al., 2008).

Following closely the exposition by Winters et al. (2010), the impact of the project on an individual can be defined as the difference between the potential outcome with $\left(Y_{l}\right)$ and without $\left(Y_{0}\right)$ treatment $(\delta)$. A commonly used measure of impact is the Average Treatment Effect on the Treated (ATET), which quantifies the impact of the project on beneficiaries, and can be expressed as:

$$
A T E T=E\left(Y_{1}-Y_{0} \mid D=1\right)=E\left(Y_{1} \mid D=1\right)-E\left(Y_{0} \mid D=1\right) .
$$

where $D=1$ if treated and 0 otherwise. The last term in equation (1) denotes the average outcome of beneficiaries had they not been treated, which is clearly not observable. Nonetheless, the expression $E\left(Y_{0} \mid D=0\right)$, the value of $Y$ for the individuals that are not treated, is observable and can be used to compute the following:

$$
\Delta=E\left(Y_{1} \mid D=1\right)-E\left(Y_{0} \mid D=0\right) \text {. }
$$

Adding and subtracting the term $E\left(Y_{0} \mid D=1\right)$ to equation (2) yields

$$
\begin{aligned}
\Delta & =E\left(Y_{1} \mid \mathrm{D}=1\right)-E\left(Y_{0} \mid D=1\right)+\left[E\left(Y_{0} \mid D=1\right)-E\left(Y_{0} \mid D=0\right)\right] \\
& =A T E T+\left[E\left(Y_{0} \mid D=1\right)-E\left(Y_{0} \mid D=0\right)\right]
\end{aligned}
$$

Therefore, the term $\Delta$ is equal to the ATET plus the expression in the square brackets, which represents the selection bias $(S B)$ originating from observable and/or unobservable variables. If $S B=0$ then the $A T E T$ is equal to the average outcome of beneficiaries minus that of the untreated or control group.

If randomization is done correctly then, on average, the observed and unobserved characteristics of treated and untreated individuals are identical except for treatment status implying that

$$
E\left(Y_{0} \mid D=1\right)=E\left(Y_{0} \mid D=0\right) .
$$

Thus, the term in the square brackets in equation (3) goes to 0 meaning that $S B=0$. The equality in (4) further indicates that the term on the left hand side, which is not observable, can be replaced in equation (1) by the term on the right hand side, which is indeed observable. In sum, in a well-executed experimental study, the impact of the intervention is the difference in the mean value for the indicator of interest between the treated and the control group. The same numerical result can be obtained by estimating the following model with ordinary least squares regression: 


$$
Y=\hat{a}_{0}+\hat{a}_{1} * D+\stackrel{\circ}{a}
$$

where $\hat{a}_{1}$ is the ATET. Data from an appropriately drawn sample of treatment and control groups after the treatment (endline) is needed to estimate the ATET (Todd 2008).

Despite the advantages of experimental designs, impact evaluation work in the agricultural sector has relied, for various reasons, largely on quasi-experimental approaches (IEG, 2011; Carter and Barrett, 2010; Ravallion, 2008). Several quasi-experimental options are available including propensity score matching (PSM), difference in difference (DID), instrumental variables and regression discontinuity (Angrist and Pischke, 2009). A robust option that has been used in several studies combines PSM with DID, which mitigates biases from observables and time invariant unobservables, respectively. This approach requires panel data; typically, baseline data collected before implementation and endline data gathered towards the end of implementation (Khandker et al., 2010). In what follows we focus on the case where only crosssectional endline data is available for both the treatment and control groups.

\section{Impact evaluation with stochastic production frontiers}

To recapitulate, we have argued that randomization makes it possible to provide unbiased measures of impact even if only (suitable) endline cross sectional data are available. If the indicator of interest is output or total value product, often used in agricultural projects and the type of indicator we have in mind here, one can visualize the impact of an intervention as an upward shift or jump in the production frontier of beneficiaries compared to the control group. In addition to measuring the jump in the frontier attributable to the intervention we are interested in exploring the managerial performance of treatment vs. control since extension assistance is frequently part of what beneficiaries get. Managerial performance, as we have argued already, can be obtained from TE measures derived from a stochastic production frontier. Therefore, the task at hand is to disentangle the technology jump from managerial performance (TE) contrasting beneficiaries with control.

Several studies have considered sample selection biases in TE measurement and have typically relied on Heckman's (1979) two-step procedure, which generates a bias-correcting variable known as the Inverse Mill's Ratio (IMR). Examples include Bradford et al. (2001) for large hospitals, and Sipiläinen and Oude Lansink (2005) for organic and conventional farms. Solís et al. (2007) analyze TE levels for hillside farmers in El Salvador and Honduras applying the Switching Regression approach which incorporates the IMR into the frontier model. Other authors have acknowledged sample selection as a potential problem in their stochastic frontier studies including Kaparakis et al. (1994), in an analysis of commercial banks, and Collins and Harris (2005), in their study of UK chemical plants; however, the issue is not addressed in their models. Mayen et al. (2010) used PSM to correct for biases from observed variables in their TE investigation of organic versus conventional US dairy farms but failed to account for biases stemming from unobservables. Rahman et al. (2009) used the Greene (2010) method, to which we return below, to analyze production efficiency for a sample of rice producers in Thailand but in this case the potential bias from observables is overlooked.

Recognizing the need to improve the methods to correct for selectivity in SPF models, Kumbhakar et al. (2009) developed an approach where the selection mechanism is assumed to operate through the one-sided error in the frontier and they apply this model to examine organic 
and conventional dairy farming in Finland. A second contribution in this area is by Lai et al. (2009) who formulate a wage equation in which the selection mechanism is correlated with the composed error in the frontier. Moreover, Greene (2010) has argued that IMR corrections are unsuitable for nonlinear models, such as the SPF. He further contends that the log likelihood in both the Kumbhakar et al. (2009) and Lai et al. (2009) papers is computationally demanding and offers an alternative model, which has been the basis for the work we have undertaken on this subject and that we summarize below.

Greene's (2010) contribution starts with the sample selection correction introduced by Heckman (1979) for linear models and with Terza's (1996, 2009) extension to non-linear models, and develops an approach to correct for selectivity in SPF models. Although Greene's application uses panel data for OECD and non-OECD countries, the model is formulated and applied by the author as if the data was cross-sectional. Readers interested in the formal model formulation are directed to the 2010 paper and here we just underscore that Greene assumes that the unobserved attributes in the selection equation are correlated with the two-sided error in the stochastic frontier.

Our interest is using an SPF model to separate the technology jump from TE levels using data generated for a quasi-experimental analysis coming from development projects where beneficiaries self-select into participation. This self-selection can be based on observables (agroecological conditions, farm size, family size, gender, etc.) and/or unobservables where managerial ability is a prominent factor. We focus on a situation where we have only crosssectional data across treatment and control groups collected at the end of the implementation of the project. To undertake this type of analysis, Bravo-Ureta, Greene and Solís (2012), hereafter BGS, combined PSM with the Greene (2010) model to deal with biases from observables and unobservables, respectively.

The BGS estimation proceeds in two basic steps. In the first step, PSM is applied using time invariant observable attributes for all units (producers) in the beneficiary and control groups to estimate a binary (Logit or Probit) model to generate propensity scores. Matching procedures, of which there are several options (see Caliendo and Kopeinig 2008), are applied and, after verifying the common support and balancing conditions, matched samples for treatment and controls corrected for biases from observables are defined. The second step is to use the matched observations to estimate separate SPF models for beneficiaries and control using the Greene (2010) model in order to obtain estimates that are corrected for both observed and unobserved attributes.

BGS apply their model to a cross-sectional data set that was generated for the impact evaluation of the MARENA Program implemented in Honduras (Bravo-Ureta et al. 2012). The results reveal that average TE is consistently higher for beneficiary farmers than the control group while the presence of selectivity bias cannot be rejected statistically. This finding suggests that better managers tend to be more inclined to participate in projects. However, the TE gap between beneficiaries and control farmers is lower for the matched samples compared to the unmatched, a result that is consistent with the fact that PSM makes both groups more similar. Moreover, the sample selection results point to a further narrowing of the TE gap.

In a subsequent analysis that uses the BGS model, González-Flores et al. (2014) employ data for a sample of small-scale potato farmers from Ecuador to explore the impact of Plataformas de Concertación on productivity. Although the results from the SPF reveal that selection bias is not statistically significant, the evidence does show that beneficiaries enjoy higher average yields than control farmers holding inputs constant. However, beneficiaries exhibit lower TE with respect to their own frontier compared to control farmers. These findings are consistent with the 
notion that, at the time the data was collected, beneficiaries were still in the "learning by doing" stage of technology adoption. Further analysis does reveal a positive association between TE and the length of time the beneficiaries were exposed to the intervention.

The final study we consider is the recent work by Villano et al. (2014) who investigate the impact of adopting certified seed varieties for a cross-sectional sample of 3,164 rice farmers in the Philippines. The authors used the BGS model to measure the technology gap, understood as the distance in the production frontiers of adopters and non-adopters, and the managerial gap defined as the difference in average TE between the two groups. These authors also estimate a meta-frontier model to compare the TE of adopters and non-adopters with respect to a common technology. The analysis shows that the use of certified seeds has a significant and positive impact on the output, TE and net income of farmers that adopt such seeds compared to those that do not. In other words, there is evidence of significant technological and managerial gaps both favoring improved seed adopters and these gaps are more pronounced after correcting for selection bias.

\section{Concluding comments}

This article has reviewed a framework developed recently, that integrates stochastic production frontiers with impact evaluation methodology, to separate the technology effect of a project from managerial performance accounting for biases from observables and unobservables within a cross-sectional data structure. Three recent studies that have applied this framework were reviewed and the results reveal that the treated do experience an upward shift in their frontiers attributable to development interventions relative to the control group, which is what would be expected. An additional and novel feature of the integrated framework is the ability to provide new evidence regarding the managerial performance of the treated versus the controls and these results are not uniform.

The next step in this research agenda is to extend the BGS methodology in order to handle two round panel data; that is, baseline and endline data, which is often the setup in impact evaluation work. This panel data analysis would provide robust results concerning changes attributable to a project for both the shift in the frontier over time and for the relative effect of the intervention on managerial performance for the treated compared to the control. A clear decomposition of these effects would have important policy implications concerning the allocation of scarce resources between activities focusing on improving the use of existing technology versus investments on interventions emphasizing the adoption and diffusion of improved technologies.

Acknowledgements. The author is grateful to Antonio Alvarez, Jeremy Jelliffe and Daniel Solís for their comments on an earlier draft.

\section{References}

Angrist, J. and Pischke, J. (2009) Mostly harmless Econometrics, Princeton University Press, New Jersey.

Barrett, C. and Carter, M. (2010) The power and pitfalls of experiments in Development Economics: some non-random reflections, Applied Economics Perspectives and Policy, $32,515-548$. 
Bradford, D, Kleit, A., Krousel-Wood, M. and Re, R. (2001) Stochastic frontier estimation of cost models within the hospital, Review of Economics and Statistics, 83, 302-309.

Bravo-Ureta, B.E., Greene, W. and Solís, D. (2012) Technical efficiency analysis correcting for biases from observed and unobserved variables: an application to a natural resource management project, Empirical Economics, 43, 55-72.

Bravo-Ureta, B.E., Solís, D., Cocchi, H. and Quiroga, R. (2006) The impact of soil conservation and output diversification on farm income in Central American hillside farming, Agricultural Economics, 35, 267-276.

Bravo-Ureta, B.E, Solís, D., Moreira, V., Maripani, J., Thiam, A. and Rivas, T. (2007) Technical efficiency in farming: a meta-regression analysis, Journal of Productivity Analysis, 27, 5772.

Caliendo, M. and Kopeinig, S. (2008) Some practical guidance on the implementation of propensity score matching, Journal of Economic Surveys, 22, 31-72.

Cavatassi, R., González-Flores, M.M., Winters, P., Andrade-Piedra, J., Espinosa, P. and Thiele, G. (2011) Linking smallholders to the new Agricultural Economy: the case of the Plataformas de Concertación in Ecuador, Journal of Development Studies, 41, 62-89.

Cooper, W.W. and Lovell, C.A.K. (2011) History lessons, Journal of Productivity Analysis, 36, 193-200.

Dinar, A., Karagiannis, G. and Tzouvelekas, V. (2007) Evaluating the impact of agricultural extension on farm's performance in Crete: a non-neutral stochastic frontier approach, Agricultural Economics, 36, 135-146.

Duflo, E., Glennerster, R. and Kremer, M. (2008) Using randomization in Development Economics research: a toolkit, in Schultz, T. and Strauss, J. (eds) Handbook of Development Economics, 3895-3962, Amsterdam: Elsevier.

Gertler, P.J., Martinez, S., Premand, P., Rawlings, L.B. and Vermeersch, C.M.J. (2011) Impact evaluation in practice, The World Bank, Washington D.C.

González-Flores, M., Bravo-Ureta, B.E., Solís, D. and Winters. P. (2014) The impact of high value markets on smallholder efficiency in the Ecuadorean sierra: a stochastic production frontier approach correcting for selectivity bias, Food Policy, forthcoming.

Fried, H.K., Lovell, C.A.K. and Schmidt, P. (eds) (2010) The measurement of productive efficiency and productivity growth, Oxford University Press: Oxford.

Greene, W. (2010) A stochastic frontier model with correction for sample selection, Journal of Productivity Analysis, 34, 15-24.

Heckman, J. (1979) Sample selection bias as a specification error, Econometrica, 47, 153-161.

Hoch, I. (1976) Production functions and supply applications for California dairy farms, Giannini Foundation Monograph, 36.

IEG (Independent Evaluation Group) (2011) Impact evaluations in Agriculture: an assessment of the evidence, Washington, DC: World Bank.

Kaparakis, E., Miller, S. and Noulas, A. (1994) Short run cost inefficiency of commercial banks: a flexible stochastic frontier approach, Journal of Money Credit and Banking, 26, 21-28.

Khandker, S.R., Koolwal, G.B. and Samad, H.A. (2010) Handbook on impact evaluation: quantitative methods and practices, The World Bank, Washington D.C..

Kumbhakar, S., Tsionas, M. and Sipilainen, T. (2009) Joint estimation of technology choice and technical efficiency: an application to organic and conventional dairy farming, Journal of Productivity Analysis, 31, 151-162. 
Lai, H., Polachek, S. and Wang, H. (2009) Estimation of a stochastic frontier model with a sample selection problem, Working Paper, Department of Economics, National Chung Cheng University.

Maffioli, A., Ubfal, D., Vázquez-Baré, G. and Cerdán-Infantes, P. (2011) Extension services, product quality and yields: the case of grapes in Argentina, Agricultural Economics, 42, 727-734.

Martin, J.P. and Page Jr, J.M. (1983) The impact of subsidies on X-efficiency in LDC industry: theory and an empirical test, The Review of Economics and Statistics, 65, 608-617.

Mayen, C., Balagtas, J. and Alexander, C. (2010) Technology adoption and technical efficiency: organic and conventional dairy farms in the United States, American Journal of Agricultural Economics, 92, 181-195.

Mundlak, Y. (1961) Empirical production function free of management bias, Journal of Farm Economics, 43, 44-56.

Rahman S., Wiboonpongse, A., Sriboonchitta, S. and Chaovanapoonphol, Y. (2009) Production efficiency of jasmine rice producers in Northern and North-Eastern Thailand, Journal of Agricultural Economics, 60, 419-435.

Ravallion, M. (2008) Evaluating anti-poverty programs, in Schultz, T. and Strauss, J. (eds) Handbook of Development Economics, Amsterdam: Elsevier, 3787-3846.

Sipiläinen, T. and Oude Lansink, A. (2005) Learning in switching to organic farming, NJFSeminar 369, NJF Report 1, Nordic Association of Agricultural Scientists.

Solís, D., Bravo-Ureta, B.E. and Quiroga, R. (2007) Soil conservation and technical efficiency among hillside farmers in Central America: a switching regression model, Australian Journal of Agricultural and Resource Economics, 51, 491-510.

Taylor, T.G. and Shonkwiler, J.S. (1986) Alternative stochastic specifications of the frontier production function, the analysis of agricultural credit programs and technical efficiency, Journal of Development Economics, 21, 149-160.

Taylor, T.G., Drummond, H.E. and Gomes, A.T. (1986) Agricultural credit programs and production efficiency: an analysis of traditional farming in Southeastern Minas Gerais, Brazil, American Journal of Agricultural Economics, 68, 110-119.

Terza, J. (1986) FIML, method of moments and two stage method of moments estimators for nonlinear regression models with endogenous switching and sample selection, Working Paper, Department of Economics, Penn State University.

Terza, J.V. (2009) Parametric nonlinear regression with endogenous switching, Econometric Reviews, 28, 555-580.

Todd, P.E. (2008) Evaluating social programs with endogenous program placement and selection of the treated, in Schultz, T. and Strauss, J. (eds) Handbook of Development Economics, Amsterdam: Elsevier, 3846-3894.

Triebs, T.P. and Kumbhakar, S.C. (2013) Production and management: does inefficiency capture management?, paper presented at the 13th EWEPA Meeting, Helsinki, Finland.

Villano, R., Bravo-Ureta, B.E., Solís, D. and Fleming, E. (2014) Modern rice technologies and productivity in The Philippines: disentangling technology from managerial gaps, manuscript.

Winters, P., Salazar, L. and Maffioli, A. (2010) Designing impact evaluations for agricultural projects, Strategy Development Division, Inter-American Development Bank, Washington D.C.

World Bank (2006) Impact evaluation: the experience of the Independent Evaluation Group of the World Bank, Independent Evaluation Group, World Bank. 